\title{
A controlled study of the effect of a mindfulness-based stress reduction technique in women with multiple chemical sensitivity, chronic fatigue syndrome, and fibromyalgia
}

\author{
Tara Sampalli' \\ Elizabeth Berlasso' \\ Roy Fox' \\ Mark Petter ${ }^{2}$ \\ 'Nova Scotia Environmental Health \\ Centre, Fall River, Nova Scotia, \\ Canada; ${ }^{2}$ Doctoral Candidate, \\ Department of Psychology, Dalhousie \\ University, Halifax, Canada
}

Correspondence: Tara Sampalli Manager and Research Director, Nova Scotia Environmental Health Centre, Capital District Health Authority, 3064 Lake Thomas Drive, Fall River, NS B2T IK6, Canada

Tel + I 9028603107

Fax +I 9028602046

Email tara.sampalli@cdha.nshealth.ca

\begin{abstract}
Background: The objective of this study was to examine the effect of a mindfulness-based stress reduction (MBSR) program on women diagnosed with conditions such as multiple chemical sensitivity (MCS), chronic fatigue syndrome (CFS), and fibromyalgia (FM).

Methods: The intervention group underwent a 10-week MBSR program. Symptoms Checklist Inventory (SCL-90R) was used as outcome measure and was administered before the start of the program (pre-), immediately upon completion (post-) and at three-month follow-up. Women on the wait list to receive treatment at the Nova Scotia Environmental Health Centre were used as control subjects for the study.
\end{abstract}

Results: A total of 50 participants in the intervention group and 26 in the wait-list controls group were recruited for this study. Global scores in the intervention group reached statistical significance pre-post $(<0.0001)$ and at pre-follow-up $(<0.0001)$ while the global scores in the control group remained the same. Five of nine and eight of nine subscales of the SCL-90R showed improvement of statistical significance in MBSR group following treatment and at three-month follow-up.

Conclusions: The study showed the importance of complementary interventions such as MBSR techniques in the reduction of psychological distress in women with chronic conditions.

Keywords: chronic conditions, multiple chemical sensitivity, mindfulness-based stress reduction, chemical sensitivity

\section{Background}

Conditions such as multiple chemical sensitivity (MCS), fibromyalgia (FM), and chronic fatigue syndrome (CFS) are a significant problem to the health care system due to the lack of effective management strategies. ${ }^{1-4} \mathrm{MCS}$ is defined as a chronic condition with reproducible symptoms involving multiple organ systems whose symptoms are produced by low levels of exposure to multiple, chemically unrelated substances and improve or resolve when the chemical agents are removed. ${ }^{5}$ The Canadian Clinical Working Case definition for FM is that the condition is categorized by a history of widespread pain and pain on palpation at 11 or more of the defined tender point sites. Patients with this condition also experience significant fatigue and cognitive problems. ${ }^{6}$ A patient receives a diagnosis of CFS if they have severe chronic fatigue of six months or longer duration with other known medical conditions excluded by clinical diagnosis and they have concurrently four or more of the following symptoms: substantial impairment in short-term memory or concentration; sore throat; tender lymph nodes; muscle pain; multi-joint pain without swelling or redness; headaches of a new type, pattern or severity; unrefreshing sleep; and post-exertional malaise lasting more than 24 hours. $^{7}$ 
Aaron and Buchwald ${ }^{8}$ reviewed the shared features of MCS, CFS, and FM such as fatigue/pain, inconsistent demonstration of laboratory abnormalities, disability out of proportion to examination findings, and association with "stress" and psychosocial factors. They found significant overlap among definitions for the core symptoms of these conditions suggesting co-morbidity of these conditions for patients.

MCS, FM, CFS, and in some cases chronic pain have been attributed to the environment. For these conditions there are no specific or standardized management strategies for treatment that have been shown to alleviate or reverse the condition. ${ }^{9-12}$ The challenges in developing standardized care lie in the number of overlapping conditions with a wide variety of symptoms which are poorly characterized, but appear to be linked to the environment. Predominantly, patients require an individualized care plan that takes into account all aspects of their illness. ${ }^{9}$ However, since these conditions are poorly understood with limited information in the literature and a multitude of overlapping symptoms and diagnoses, they often leave health care professionals challenged when attempting to develop a management strategy. These problems may be recognized by the patients, and this may lead to requests for referral to multiple specialists and the ordering of various costly laboratory tests. ${ }^{13}$ Patients also learn to move beyond the traditional medical approach and begin to manage their own treatment. ${ }^{14,15}$

The Nova Scotia Environmental Health Centre (NSEHC) is a medical facility with a mandate for treatment and research of medical conditions such as MCS, CFS, and FM. ${ }^{16,17}$ At the NSEHC, a multidisciplinary approach to treatment is taken in which the various disciplines work together in generating information on all aspects of the patient's illness before developing an individualized care plan for every patient. Research at the NSEHC is targeted towards understanding the nature of these illnesses, type and extent of symptom occurrence and their triggers, and the study of effective management strategies. Published research has added to our knowledge base of patients with MCS. Joffres and colleagues ${ }^{13}$ looked at the prevalence of major symptoms in 351 patients from the NSEHC. General symptoms such as difficulty concentrating, fatigue, forgetfulness, and irritability dominated the overall prevalence of symptoms since the start of their illness. Those related to irritation such as sneezing, itchy or burning eyes, and hoarseness or loss of voice were more common when exposed to environmental stressors. A review of 100 patients $^{18}$ who fulfilled the consensus criteria for $\mathrm{MCS}^{5}$ has shown that major senses are frequently reported as being modified, with $88 \%$ of patients reporting increased sense of smell, 74\% reporting light sensitivity and $74 \%$ reporting sound sensitivity. Another study conducted at the NSEHC, ${ }^{19}$ investigated the ability to adapt to environmental challenges in individuals with and without MCS. Using a variety of physiological readings (skin conductance, skin temperature, respiratory rate, surface electromyography, and heart rate) and from self-reported symptoms, we showed evidence that the majority of participants are in a heightened state of reactivity or central nervous system arousal and have altered sensitivity in the five major senses. Subjects with chemical sensitivities took longer to adapt to baseline protocols such as variation in noise levels in the booth environment, than did controls. After adaptation (stability in physiological measures to baseline protocols), despite small study numbers, individuals with MCS displayed statistically significant responses $(p<0.02)$ in tonic skin conductance response to test substances compared with controls and compared with the control substance. Reported symptoms were also higher in cases than in controls for the test substances, body wash solution $(p=0.05)$ and dryer sheets $(p=0.02)$.

Clinical evaluations at the NSEHC have revealed that the patient population may have to cope with a variety of biopsychosocial stressors in addition to the symptoms and stressors related to their illness. This additional stress may have a negative impact on their health and well being. Despite the concise definition for $\mathrm{MCS},{ }^{5}$ patients who receive this diagnosis often report being subjected to a variety of biases and misinterpretations from within the medical community, employers, family, and friends. Some of our patients report marginalization and negative labeling such as malingering or neurotic personality disorders. ${ }^{20}$ For patients who are desperate to feel well, and want to live as productive members of society in their work/ professions and interpersonal relationships, this adds another layer of stress of being misunderstood and viewed through the lens of a psychiatric disorder. In extreme cases, this may lead individuals to become fearful and skeptical of doctors, employers, insurance caseworkers, the justice system, and other agencies that become involved in an attempt to provide answers, solutions, and support to their state of illness and disease. While this may not be the only cause for the stress experienced by individuals with this diagnosis, it could add to the overall perception of stress in the management of their illness. The goal of the care management at the NSEHC is to address the whole person and offer interventions that can strengthen resiliency towards management of the illness and build coping skills to all types of stressors.

The Body Mind Awareness Program, an approach based on the Mindfulness-Based Stress Reduction model, ${ }^{21,22}$ was initiated as a pilot project in 1997 and, given its initial success, was subsequently incorporated into the stream of 
interventions and treatment options available to individuals at the NSEHC. The Body Mind Awareness Program (BMAP) at the NSEHC follows the guidelines of the original MBSR program developed by Jon Kabat-Zinn. ${ }^{21}$ Illness is a major stressor, and how one copes with stress has consequences for health outcomes. Results from other trials using the MBSR approach have shown that it is effective in reducing anxiety, depression, pain, and psychological symptoms associated with illness. $^{22-29}$

Evaluations based on anecdotal reports collected at the end of each BMAP program have revealed the beneficial nature of this technique as applied to individuals seeking treatment at the NSEHC. Patients report feeling less anxious, less depressed, use less pain medication, experience better sleep, and achieve a better quality of life. A controlled study was thus undertaken to quantify these narratives and identify the type and extent of changes in patients undergoing intervention versus wait-list controls using the Symptoms Checklist Inventory (SCL-90R). ${ }^{30}$

\section{Methods \\ Study participants}

The objective of the study was to determine the impact and extent of changes in women diagnosed with MCS, CFS, and FM following the BMAP intervention when compared to a group of individuals that were waiting to be seen at the NSEHC. Participants for the intervention group were selected from women who received a referral to BMAP from a physician at the NSEHC. The intervention group in the study continued to receive the usual care management that was essential to manage their illness. The control group consisted of the first 50 women from the wait list group who consented to participate in the study.

\section{Study design}

The study compared the results of a 10-week intervention group that underwent training in the MBAP to a control group that was comprised of women waitlisted to be seen as patients at the NSEHC. The participants were screened for the following exclusionary criteria: subjects with major illnesses such as cancer; and subjects with an untreated psychiatric disorder and that might be negatively affected by the program or that might affect the group process. Medication type and usage were assessed for all participants during the study.

There were no people excluded on the basis of the outlined criteria for this study. Men who participated in the BMAP intervention were excluded from the study sample since women were a fair representation of the patient population. ${ }^{13}$
Following the receipt of informed consent, an intervention group undertook 10-week training in mindfulness-based stress reduction of 2.5 hours each week, in addition to committing to a daily home practice. The study received ethical approval by the Capital District Health Authority Ethics Committee.

\section{Body mind awareness program - mindfulness-based stress reduction model} The BMAP typically consists of 10 weekly group meetings, each one lasting approximately 2.5 hours. The facilitator is trained in MBSR through the Omega Institute, Rhinebeck, New York with 12 years experience in facilitating the BMAP intervention. Each session provides an opportunity for participants to share their experiences of the week of mindfulness practice of the body scan, sitting meditation, or mindfulness yoga. Patients learn about the psychophysiology of stress and emotions. One session is reserved as a silent "retreat" of six hours at week 8 of the program. Commitment to the homework exercises which involve the practice of mindfulness both formally (sitting meditation, yoga, and body scan) and informally (eating, cooking, driving, and other day-to-day activities) is an essential component of the program. With the guidance and support from the instructor, participants begin to generalize what they learn in class and in daily home practice towards the management of their daily lives and their illness challenges in particular.

Participants are provided with compact discs that guide them through the formal mindfulness practices: yoga, mindfulness meditation practices, and the body scan. In addition, as the practices develop, patients are introduced to the concept that thoughts are not facts and that one can develop the ability to respond to stressors, rather than react to them. The goal is to help participants become more aware of thoughts, feelings, and sensations and their inter-related connections.

To ensure the consistent application of the principles learned, a workbook is provided for each person to follow throughout the intervention. With the commitment to repeated mindfulness practices, participants begin to develop the ability to step out of habitual reactive patterns or negativethinking patterns that might otherwise escalate to a cycle of stress reactivity and a heightened arousal state during stressful life-moments.

\section{Outcome measures and statistical analysis}

The intervention group answered the SCL-90R pre- and post-intervention (before commencement of BMAP intervention and at the end of 10 -week intervention) and at a 
three-month follow-up. SCL-90R was administered to the control group at the same time periods. In a clinical evaluation conducted at the NSEHC using SCL-90R, Brief Symptoms Inventory, McGill Pain Questionnaire and WHOQOL-BREF (World Health Organization Quality of Life), SCL-90R was identified as the most compelling outcome for BMAP based on the consistency and sensitivity in capturing the changes pre and post intervention. Data analysis for this study utilized SAS (version 9.1; SAS Institute Inc., Cary, NC, USA), and the usual procedures for continuous data (t-test, analysis of variance, general linear model [GLM]) and categorical data (SAS processes: FREQ, LOGISTIC).

\section{Results}

The study included 50 women in the intervention group and 26 women in the control group. Mean age of participants in the intervention group was 46.5 (standard deviation $[\mathrm{SD}]=9.3$, range $=35-64)$ and in the control group was $44.5(\mathrm{SD}=8.5$, range $=32-60)$.

Approximately $16 \%$ of the total recruited participants dropped out of the intervention group for reasons such as work commitments, deterioration in health, or family reasons. In the control group, 26 of the 50 wait-listed patients approached for participation completed the questionnaires at the set time periods (pre-, post-, and follow up) and became a part of the study sample. $76 \%$ of the intervention group had a diagnosis of MCS in combination with FM and CFS, 15\% had a diagnosis of FM, and the remaining participants had a diagnosis of CFS. The wait-list control group had not received a diagnosis from the NSEHC's physician at the time of recruitment. The group comprising all women, was selected because they had a referral to be seen at the NSEHC.

Independent sample t-tests were used to compare SCL90-R Global Severity Index (GSI) and subscale scores between the wait-list control and MBSR treatment group at baseline, posttreatment (10 weeks), and three-month follow-up. Results are summarized in Table 1. The two groups were equal on GSI scores at baseline, with the MBSR treatment group having significantly lower scores than the control group at post-treatment $(\mathrm{t}[74]=2.35, \mathrm{p}<0.05)$, and at follow-up $(\mathrm{t}[74]=3.86, \mathrm{p}<0.001)$. All subscale scores except for the somatization subscale were equal at baseline between the two groups. Five of nine subscales were significantly lower for the MBSR group following treatment, and eight of nine subscales were significantly lower for the MBSR group at three-month follow-up as summarized in Table 1. Paired samples tests were used to compare changes in SCL90-R GSI and subscale scores from baseline to post-treatment and from post-treatment to three-month follow-up, within each group. The long-term effects of treatment were examined using a GLM repeatedmeasures procedure for the GSI, as well as the somatization, anxiety, and depression subscales, with treatment group as the between-subject variable and time (baseline, post-treatment, and follow-up) as the within-subject variable. A significant group $\times$ time interaction would indicate the presence of a treatment effect. A significant group $\times$ time interaction was found for GSI $(F[2,73]=6.83, p<0.01)$, as well as the depression $(\mathrm{F}[2,73]=7.88, \mathrm{p}<0.01)$ and anxiety $(\mathrm{F}[2,73]=3.15$, $\mathrm{p}<0.05$ ) subscales, but no significant interaction was found for the somatization subscale $(F[2,73]=0.773$, not significant $)$.

\section{Discussion}

The broader objective of the study was to determine the efficacy of a MBSR approach (BMAP) in individuals with conditions such as MCS, CFS, and FM. Results from other trials using the MBSR approach have shown reductions in anxiety, depression, pain, and psychological symptoms associated with illness. Clinical evaluations conducted at the NSEHC have shown that BMAP is able to alleviate some of the stressful symptoms of MCS, CFS, and FM, and promotes a sense of well being in our patient population. Also, our research has shown individuals with MCS exist in a state of hypervigilance ${ }^{19}$ and BMAP is targeted towards altering this state of arousal. This study was an attempt to quantify the positive changes and benefits reported by NSEHC patients upon completion of the BMAP as measured in our clinical evaluations, and compare the outcome with women that were waiting to receive intervention, wait-list controls.

The type and the extent of changes measured in the intervention group were consistent with the reports measured in clinical evaluations between 1998 and 2003 conducted at the NSEHC. The results show significant improvements in the intervention group in the GSI scores of the SCL-90R at preto post- and pre-intervention to follow-up when compared to the control group. While the scores for the control group stayed the same at pre-, post- and follow-up intervention, the intervention group showed significant improvements postintervention and at three-month follow-up. Some of these changes are significant findings for this patient population. However, it would be too simplistic to draw a linear causal relationship between environmental illness and psychological responses. The sheer complexity of the relationship between being human and responding to the physical environment may heighten or accentuate the influence of a variety of stressors. While it is hard to draw a linear relationship, it is possible to delve into some thoughts around the significance 
Table I Mean (SD) SCL-90R scores and p-values within groups by time (pre- to post-, and post- to follow-up)

\begin{tabular}{|c|c|c|c|c|c|c|c|c|c|c|}
\hline $\begin{array}{l}\text { SCL-90R } \\
\text { Scale }\end{array}$ & $\begin{array}{l}\text { BMAP: } \\
\text { Pre } \\
\text { Mean } \\
\text { (SD) }\end{array}$ & $\begin{array}{l}\text { BMAP: } \\
\text { Post } \\
\text { Mean } \\
\text { (SD) }\end{array}$ & $\begin{array}{l}\text { BMAP: } \\
\text { FUP } \\
\text { Mean } \\
\text { (SD) }\end{array}$ & $\begin{array}{l}\text { Pre- } \\
\text { Post } \\
\text { t-test } \\
\text { p value }\end{array}$ & $\begin{array}{l}\text { Post- } \\
\text { FUP } \\
\text { t-test } \\
\text { p value }\end{array}$ & $\begin{array}{l}\text { Con: } \\
\text { Pre } \\
\text { Mean } \\
\text { (SD) }\end{array}$ & $\begin{array}{l}\text { Con: } \\
\text { Post } \\
\text { Mean } \\
\text { (SD) }\end{array}$ & $\begin{array}{l}\text { Con: } \\
\text { FUP } \\
\text { Mean } \\
\text { (SD) }\end{array}$ & $\begin{array}{l}\text { Pre- } \\
\text { Post } \\
\text { t-test } \\
\text { p value }\end{array}$ & $\begin{array}{l}\text { Post- } \\
\text { FUP } \\
\text { t-test } \\
\text { p value }\end{array}$ \\
\hline Somatization & $\begin{array}{l}13.30 \\
(7.47)\end{array}$ & $\begin{array}{l}10.30 \\
(5.93)\end{array}$ & $\begin{array}{l}8.50 \\
(6.14)\end{array}$ & $<0.001$ & $<0.01$ & $\begin{array}{l}19.92 \\
(10.38)\end{array}$ & $\begin{array}{l}17.92 \\
(10.11)\end{array}$ & $\begin{array}{l}|7.3| \\
(8.87)\end{array}$ & 0.29 & 0.72 \\
\hline $\mathrm{O}-\mathrm{C}$ & $\begin{array}{l}14.66 \\
(8.97)\end{array}$ & $\begin{array}{l}10.72 \\
(5.87)\end{array}$ & $\begin{array}{l}8.32 \\
(4.71)\end{array}$ & $<0.001$ & $<0.001$ & $\begin{array}{l}13.77 \\
(10.34)\end{array}$ & $\begin{array}{l}12.31 \\
(11.03)\end{array}$ & $\begin{array}{l}13.38 \\
(9.27)\end{array}$ & 0.5 & 0.47 \\
\hline I-S & $\begin{array}{l}7.70 \\
(5.57)\end{array}$ & $\begin{array}{l}5.14 \\
(3.49)\end{array}$ & $\begin{array}{l}4.26 \\
(3.37)\end{array}$ & $<0.001$ & $<0.01$ & $\begin{array}{l}7.96 \\
(8.88)\end{array}$ & $\begin{array}{l}6.73 \\
(8.05)\end{array}$ & $\begin{array}{l}7.58 \\
(9.46)\end{array}$ & 0.46 & 0.56 \\
\hline Depression & $\begin{array}{l}15.42 \\
(9.19)\end{array}$ & $\begin{array}{l}9.36 \\
(5.82)\end{array}$ & $\begin{array}{l}7.78 \\
(5.34)\end{array}$ & $<0.001$ & $<0.01$ & $\begin{array}{l}14.73 \\
(11.32)\end{array}$ & $\begin{array}{l}15.23 \\
(12.36)\end{array}$ & $\begin{array}{l}15.53 \\
(11.86)\end{array}$ & 0.82 & 0.89 \\
\hline Anxiety & $\begin{array}{l}8.48 \\
(6.13)\end{array}$ & $\begin{array}{l}6.26 \\
(5.62)\end{array}$ & $\begin{array}{l}4.46 \\
(3.07)\end{array}$ & $<0.05$ & $<0.05$ & $\begin{array}{l}8.04 \\
(7.27)\end{array}$ & $\begin{array}{l}8.62 \\
(7.78)\end{array}$ & $\begin{array}{l}7.04 \\
(7.20)\end{array}$ & 0.66 & 0.23 \\
\hline Hostility & $\begin{array}{l}3.86 \\
(3.51)\end{array}$ & $\begin{array}{l}3.38 \\
(2.62)\end{array}$ & $\begin{array}{l}2.64 \\
(2.24)\end{array}$ & ns & $<0.05$ & $\begin{array}{l}2.58 \\
(2.76)\end{array}$ & $\begin{array}{l}2.27 \\
(2.39)\end{array}$ & $\begin{array}{l}2.73 \\
(2.86)\end{array}$ & 0.60 & 0.30 \\
\hline Phobic & $\begin{array}{l}2.68 \\
(3.19)\end{array}$ & $\begin{array}{l}1.66 \\
(1.89)\end{array}$ & $\begin{array}{l}1.40 \\
(1.56)\end{array}$ & $<0.01$ & ns & $\begin{array}{l}3.19 \\
(4.74)\end{array}$ & $\begin{array}{l}2.96 \\
(3.67)\end{array}$ & $\begin{array}{l}3.15 \\
(4.39)\end{array}$ & 0.66 & 0.57 \\
\hline Paranoid & $\begin{array}{l}5.00 \\
(3.36)\end{array}$ & $\begin{array}{l}3.16 \\
(2.48)\end{array}$ & $\begin{array}{l}2.58 \\
(2.15)\end{array}$ & $<0.001$ & $<0.05$ & $\begin{array}{l}4.27 \\
(3.92)\end{array}$ & $\begin{array}{l}4.62 \\
(5.11)\end{array}$ & $\begin{array}{l}4.77 \\
(4.42)\end{array}$ & 0.56 & 0.84 \\
\hline Psychoticism & $\begin{array}{l}4.52 \\
(4.44)\end{array}$ & $\begin{array}{l}2.70 \\
(3.11)\end{array}$ & $\begin{array}{l}2.36 \\
(2.53)\end{array}$ & $<0.01$ & ns & $\begin{array}{l}5.15 \\
(5.64)\end{array}$ & $\begin{array}{l}5.54 \\
(5.43)\end{array}$ & $\begin{array}{l}4.46 \\
(5.19)\end{array}$ & 0.47 & 0.91 \\
\hline GSI & $\begin{array}{l}84.10 \\
(44.67)\end{array}$ & $\begin{array}{l}59.78 \\
(27.38)\end{array}$ & $\begin{array}{l}47.56 \\
(21.59)\end{array}$ & $<0.001$ & $<0.001$ & $\begin{array}{l}88.27 \\
(62.65)\end{array}$ & $\begin{array}{l}83.77 \\
(62.17)\end{array}$ & $\begin{array}{l}84.08 \\
(60.09)\end{array}$ & 0.67 & 0.97 \\
\hline
\end{tabular}

Abbreviations: BMAP, body mind awareness program; Con, wait list control group; FUP, follow-up; GSI, global severity index; I-S, interpersonal sensitivity; ns, not significant; O-C, obsessive-compulsive; SCL-90R, symptoms checklist inventory; SD, standard deviation.

of these changes based on the anecdotal reports from our clinical evaluations and the results using SCL-90R from this study.

Post-intervention improvements were observed in the following SCL-90R subscales: somatization, depression, phobic anxiety, and paranoid ideation. The stressor of phobic anxiety of the environmental stressors, perceived as threatening can be disproportionate to the offending trigger. This trend showed statistical improvement in the participants of the BMAP at post-program to a three-month follow-up.
As is the case of a large proportion of the environmentally sensitive patients at the NSEHC, they receive a referral to the NSEHC following a significant investment of time, energy, and resources in the health care system to "find an answer" to their problems. Often they are met with disdain, disbelief, ridicule, and a referral to psychiatry, which is to say their illness is "all in their heads" further complicating a poorly understood and difficult-to-treat collection of conditions. Disordered thinking traits also changed post-intervention as seen in the positive changes of the somatization subscale 
of the SCL-90R. The characteristics of projective thought of feeling unsafe in ones' personal environment, hostility towards health care and insurance providers, suspiciousness, grandiosity, fear of loss of autonomy and delusions were shown to improve. In the BMAP, a central component of the training is recognizing thoughts as mental events and not as absolute truths or facts. Participants practice becoming aware of the cascade of habits of mind such as catastrophizing, victimizing, and rumination. Daily practice encourages a broader perspective of thoughts and images passing through the mind and by turning attention to the breath brings acceptance to the present moment without judgment of pleasant, unpleasant or neutral feelings. In this way resiliency to seeing things as they are, and gaining some distance and perspective on them begin to take hold. This perhaps creates awareness that there may be other ways to think about situations, and thus find freedom from the domination of old thought patterns that pop up automatically.

At the three-month follow-up, other changes with the intervention group that showed statistical significance were traits of obsessive compulsiveness, interpersonal sensitivity, anxiety and psychosis. The obsessive nature of thoughts, and "safe" behaviors (such as avoidance or isolation) was greatly improved with the BMAP intervention; feelings of inferiority or inadequacy because of an unexplainable health condition, self-doubt about their health and ability to regain healthy functioning, and self-deprecation are also characteristic features of depressed mood states. The nature of practicing daily homework and attending weekly classes in a group format provided a forum for consistency, discipline, self-responsibility, camaraderie and trust, and an increased sense of self mastery which helped to mitigate the negative side-effects of negative mood states.

A number of factors modulate the impact of health and wellness on an individual: personality factors, anxiety, coping skills and the psychological context within which environmental stressors function. The BMAP is a means for such individuals to alleviate psychosocial/life stressors that may help change the state of arousal, strengthen inner resiliency to mitigate the negative effects of stressors associated with illness, and develop healthy coping skills for the management of their illness.

\section{Limitations}

The study was not conducted in a randomized design which would have enhanced the quality of the research study. However, we considered it unethical for patients to wait to receive treatment following a long wait time to receive the appropriate referral to receive timely care. Using wait-list controls with a non-biased selection process which involved using the first 50 women to provide consent was an efficient way to obtain a control group for the study. The wait-list patients typically waited from 4-6 months to receive treatment at the NSEHC, and hence it was convenient to choose this group to measure changes at 0,10 weeks, and threemonth follow-up time periods. Subscales of the SCL-90R that have shown trends of change or getting close to statistical significance might have reached statistical significance with a larger sample size.

\section{Conclusion}

The study has shown the importance of a MBSR intervention as a complement to the mainstream management strategies for patients with MCS, CFS, and FM in improving psychological distress and strengthening mental and physical resiliency to disease management. Most importantly, with this training format and experiential teaching to embrace the present moment, the locus of control ${ }^{31}$ shifts back to the patient as they learn to reconstruct their lives independent from external measures such as success, approval and compliancy, and reconnect with the power of choice in their lives and control over their circumstances to live happier and productive lives.

\section{Disclosure}

The authors report no conflicts of interest in this work.

\section{References}

1. Geertrudis AM, Van Den Bos. The burden of chronic diseases in terms of disability, use of healthcare and health life expectencies. Eur J Public Health. 1995;5(1):29-34.

2. Weiss K, Sullivan S. The health economics of asthma and rhinitis: assessing the economic impact. J Allergy Clin Immunol. 2001;107:3-8.

3. Litt J, Tran N, Malecki K, Neff R, Resnick B, Burke T. Identifying priority health conditions, environmental data and infrastructure needs: A synopsis of the pew environmental health tracking project. Environ Health Perspect. 2004;112(14):1414-1418.

4. Kipen H, Fiedler N. Environmental factors in medically unexplained symptoms and related syndromes: The evidence and the challenge. Environ Health Perspect. 2002;110(4):597-599.

5. Bartha L, Baumzweiger W, Buscher DS. Multiple chemical sensitivity: A 1999 consensus. Arch Environ Health. 1999;54:147-149.

6. Wolfe F. Fibromyalgia: On criteria and classification. J Musculoskeletal Pain. 1994;2(3):23-39.

7. Fukuda K, Straus S, Hickie I, Sharpe M, Dobbins J, Komaroff A. The chronic fatigue syndrome: a comprehensive approach to its definition and study. International Chronic Fatigue Syndrome Study Group. Ann Intern Med. 1994;121(12):953-959.

8. Buchwald D, Garrity D. Comparison of patients with chronic fatigue syndrome, fibromyalgia, and multiple chemical sensitivities. Arch Intern Med. 1994;154:2049-2053.

9. Hessl SM. Management of patients with multiple chemical sensitivities at occupational health clinics. Occup Med. 1987;2:779-789. 
10. Lax MB. Multiple chemical sensitivities: The social construction of an illness. Int J Health Serv. 1998;28:725-745.

11. Richardson RD, Engel CC Jr. Evaluation and management of medically unexplained physical symptoms. Neurologist. 2004;10(1):18-30.

12. Sparks PJ. Diagnostic evaluation and treatment of the patient presenting with idiopathic environmental intolerance. Occup Med. 2000;15: 601-609.

13. Joffres MR, Williams T, Sabo B, Fox RA. Environmental sensitivities: Prevalence of major symptoms in a referral centre: The Nova Scotia Environmental Sensitivities Research Centre Study. Environ Health Perspect. 2001;109(2):161-165.

14. McDonald IG, Daly J, Jelinek VM, Panetta F, Gutman JM. Opening Pandora's box: The unpredictability of reassurance by a normal test result. BMJ. 1996;313:329-332.

15. Nimnuan C, Hotopf M, Wessely S. Medically unexplained symptoms: how often and why are they missed? Q J Med. 2000;93:21-28.

16. Fox RA, Sampalli T, Fox J. Measuring health outcomes of a multidisciplinary care approach in individuals with chronic environmental conditions using an abbreviated symptoms questionnaire. Journal of Multidisciplinary Healthcare. 2008;1:97-104.

17. Fox RA, Joffres MR, Sampalli T, Casey J. The impact of a multidisciplinary, holistic approach to management of patients diagnosed with multiple chemical sensitivity on health care utilization costs: an observational study. J Altern Complement Med. 2007;13(2): 223-229.

18. Fox R. The Environment and Multiple Chemical Sensitivity. Indoor Air 2002 - Proceedings of the 9th International Conference on Indoor Air Quality \& Climate.

19. Joffres MR, Sampalli T, Fox RA. Physiologic and symptomatic responses to low-level substances in individuals with and without chemical sensitivities: A randomized controlled blinded pilot booth study. Environ Health Perspect. 2005;113(9):1178-1183.

20. Anderson M, Hartz A, Nordin T, et al. Community physicians' strategies for patients with medically unexplained symptoms. Fam Med. 2008;40(2):111-118.
21. Kabat-Zinn J, Massion AO, Kristeller J, et al. Effectiveness of a meditation-based stress reduction program in the treatment of anxiety disorders. Am J Psychiatry. 1992;149(7):936-943.

22. Kabat-Zinn J. Full catastrophe living: using the wisdom of to your body and mind to face stress, pain, and illness. New York, NY: Dell Publishing; 1990.

23. Astin JA. Stress reduction through mindfulness meditation. Effects on psychological symptomatology, sense of control, and spiritual experiences. Psychother Psychosom. 1997;66(2):97-106.

24. Astin JA, Berman BM, Bausell B, Lee WL, Hochberg M, Forys KL. The efficacy of mindfulness meditation plus Qigong movement therapy in the treatment of fibromyalgia: a randomized controlled trial. J Rheumatol. 2003;30(10):2257-2262.

25. Carlson LE, Ursuliak Z, Goodey E, Angen M, Speca M. The effects of a mindfulness meditation-based stress reduction program on mood and symptoms of stress in cancer outpatients: 6-month follow-up. Support Care Cancer. 2003;9(2):112-123.

26. Kabat-Zinn J, Lipworth L, Burney R. The clinical use of mindfulness meditation for the self-regulation of chronic pain. J Behav Med. 1985;8(2):163-190.

27. Miller JJ, Fletcher K, Kabat-Zinn J. Three-year follow-up and clinical implications of a mindfulness meditation-based stress reduction intervention in the treatment of anxiety disorders. Gen Hosp Psychiatry. 1995;17(3):192-200.

28. Speca M, Carlson LE, Goodey E, Angen M. A randomized, wait-list controlled clinical trial: the effect of a mindfulness meditation-based stress reduction program on mood and symptoms of stress in cancer outpatients. Psychosom Med. 2000;62(5):613-622.

29. Tacón AM, McComb J, Caldera Y, Randolph P. Mindfulness meditation, anxiety reduction, and heart disease: a pilot study. Fam Community Health. 2003;26(1):25-33.

30. Derogatis LR. The SCL-90R: Administration Scoring and Procedures Manual II. Baltimore, MD: Clinical Psychometric Research; 1992.

31. Rotter J. Generalized expectations for internal versus external control of reinforcements. Psychological Monographs, 80, Whole No. 609. 
